\title{
Existential, Possessive and Locative Constructions in Yami Language: A comparative study to Formosan languages *
}

\author{
Chihjen Cheng ** \\ (Tunghai University, China)
}

\begin{abstract}
This study reports on Yami existential, possessive and locative constructions, regarding the issues on (i) two 'HAVE' structures, (ii) Definiteness Effect (DE) and (iii) an analysis of small clause, in terms of a formal syntactic approach. Compared with Formosan languages, Yami syntactically shows the differences based on two 'HAVE' structures. Besides, it is also proved that Definiteness Effect in Yami differs from that in other Formosan languages, such as Bunun language. Finally, this study also argues that the existential verb amian/abo 'exist/not exist' in Yami selects a small clause as its complement, representing a relative clause.
\end{abstract}

Keywords: existential, possessive, locative, Yami (language), Definiteness Effect, small clause

\section{Introduction}

\subsection{Related issues in language}

Existential, possessive and locative constructions have been extensively reported in details in various languages, such as English, Mandarin Chinese, and Formosan languages, from different perspectives, for instance, syntactic, semantics, cognitive and so forth (Lyons, 1967; Kuno, 1971; Huang, 1987; Zeitoun et al, 1999; Wu, 2009; among others). However, there are few studies concerning existential, possessive and locative constructions of Yami language, spoken in Orchid Island, and viewed as a Batanic branch of the Philippine languages, which is one of Malayo-Polynesian languages of the Austronesian language family. That is one of the reasons why the studies of Formosan languages rarely report on Yami's existential, possessive and locative constructions. Yami language is a verb-initial language, and it has flexible word order variations (Rau \& Dong, 2006; Blust, 2009; Lapolla \& Poa, 2006) to manifest the different constructions by its case

\footnotetext{
* I hereby give my thanks to the scholars who have given me helpful comments and suggestions on this paper: V. Rau, M-N. Dong, A. H. Chang, S. Shih as well as two anonymous reviewers.

${ }^{* *}$ Chihjen Cheng: Research Assistant, Department of Foreign Languages and Literature, College of Arts, Tunghai University, Taiwan, China. E- mail: adamchjcheng@gmail.com.
} 
markers as well. Yami language ${ }^{(1)}$ also shows its language-specific properties in existential, possessive and locative constructions, for instance, the existential construction differs from the locative construction in its word order and case markers.

There are two relevant studies, concerning existential, possessive and locative constructions in Formosan languages (the subgroup of Austronesian language family): Zeitoun et al (1999) and Wu (2009).

\subsection{Previous research}

Zeitoun et al point out that the existential verb (AFFIRM)/negator (NEG) ${ }^{(2)}$ in several Formosan languages, which shares the same form with that of possession rather than the locative verb. Then, the existential verb/negator, in some others, shares the same form with the locative and possessive ones. Another situation is that the existential verb, in still others, shares the same form with the locative and possessive ones while the existential negator shares the form with the possessive one, not that of location.

In addition, Zeitoun et al mention two 'HAVE' structures in existential, possessive and locative constructions of Formosan languages. Indeed, Freeze (1991 \& 1992) notes that two 'HAVE' structures are found cross-linguistically, and they are (a) Y has X and (b) Y's $\mathrm{X}$ exists. Several Formosan languages display the first type only, such as Saisiyat and Paran Seediq, while most Formosan languages only display the second, for instance, Amis and Paiwan. Four Formosan languages display both types, namely Bunun, Kavalan, Puyuma and Mantauran Rukai (discussed in section 3.2).

In part of Definiteness Effect (hereafter DE), Zeitoun et al point out that four Formosan languages, Bunun, Kavalan, Puyuma and Mantauran Rukai included, have nominal case marking systems which involve a common referential/nonreferential distinction affecting both the case markers permitted in such constructions and their interpretations (discussed in section 4 ).

Finally, Zeitoun et al point out that word order variations in existential, possessive and locative constructions, and Zeitoun et al further note that it has been shown crosslinguistically that existential and locative constructions syntactically differ in terms of word order: locative phrases (LPs)/prepositional phrases (PPs) follow existential verbs in locative constructions whereas LPs/PPs will be in the sentence-final position in existential constructions.

$\mathrm{Wu}(2009)$ demonstrates Isbukun Bunun existential constructions. Isbukun is one of the dialects of Bunun in Taiwan. Wu first illustrates how peculiar morphological and syntactic

\footnotetext{
(1) The examples of Yami E, P and L construction refer to Yami Online Dictionary, Yami Digital Archives and Yami E-Learning, edited by Rau \& Dong (2007), and are partially re-created into new sentences. In addition, the given examples refer to Chang (2000), Rau \& Dong (2000, 2006 and 2013) as well.

(2) The existential verb indicates the affirmative (AFFIRM) form in this study, not negative (NEG) form.
} 


\section{Existential, Possessive and Locative Constructions in Yami Language: A comparative study to Formosan languages}

properties of the theme NPs (=DPs) in Isbukun Bunun existential constructions can be derived by means of an expletive account. Thus, Isbukun Bunun existential constructions which $\mathrm{Wu}$ investigates include structural Case marking, the emergence of definiteness restrictions, and the resistance of theme NPs (=DPs) to A'-extraction. Secondly, the study also argues for the analysis of a small clause of existential constructions in Isbukun Bunun, based on its word orders, island effects, the comparison with possessive constructions, and the coordination facts. Wu argues that Bunun existential verb selects a small clause as its sole internal argument.

Moreover, $\mathrm{Wu}$ investigates that $\mathrm{DE}$ plays an influential role in existential, possessive and locative constructions in Isbukun Bunun. She claims that definite determiners, such as -a/an 'that/this', adaiza 'that', sikaupa 'this' and proper names, cannot occur in existential, possessive and locative constructions (discussed in section 4 as well). Finally, she contends that a Bunun existential verb/negator selects a small clause as its complement from a formal-syntactic analysis (see also in Stowell, 1981; Safir, 1982; Paul, 2000).

In other words, Wu provides a description of the general properties in Bunun existential, possessive and locative constructions and a possible characterization of how these properties are derived according to the theory of grammar. Besides, she shows that the theme NP (=DP) in Bunun existential, possessive and locative constructions is not the pivot but rather stays within the VP and constitutes some structural relationship with a covert expletive. Moreover, $\mathrm{Wu}$ argues that existential, possessive and locative constructions in Isbukun Bunun cannot be analyzed along the lines of the complex NP/DP account nor the NP-XP analysis while they must receive a clausal treatment.

Rau \& Dong $(2006,2018)$ briefly provide a descriptive picture of Yami existential, possessive and locative constructions, as shown in (1), respectively.

\begin{tabular}{|c|c|c|c|c|c|c|c|}
\hline (1) a. $y a$ & m-ian & so & tao & do & vahay & $d a$. & \\
\hline AUX & AF-have & OBL & human & LOC & house & 3P.GEN & \\
\hline \multicolumn{8}{|c|}{ 'There is someone in their house.' } \\
\hline b. $y a$ & m-ian & $o$ & savong & no & tamek & $d o$ & makaves. \\
\hline AUX & AF-have & $\mathrm{NOM}$ & flower & GEN & grass & LOC & woman \\
\hline \multicolumn{8}{|c|}{ 'The woman has the flower.' } \\
\hline c. $y a$ & $m$-ian & do & vahay & $d a$ & $o$ & mavakes. & \\
\hline AUX & AF-be.at & LOC & house & 3P.GEN & NOM & woman & \\
\hline
\end{tabular}

'The woman is at their house.'

Based on Zeitoun et al (1999), Wu (2009) and Rau \& Dong (2006, 2018), the former two report in details on existential, possessive and locative constructions in Formosan languages, spoken in Taiwan, whereas Rau \& Dong briefly delineate the background of Yami existential, possessive and locative constructions. However, there are fewer previous 


\section{Chihjen Cheng}

studies concerning existential, possessive and locative constructions in Yami language in terms of a formal syntactic analysis.

\subsection{This study}

It was discussed by Zeitoun et al (1999) that even though existential and possessive constructions may syntactically or semantically differ from the locative constructions in Formosan languages, the existential and possessive constructions in Yami language however share the same existential verbs/negators with the locative construction. Rau \& Dong (2000, 2006 \& 2013) and Rau (2005) demonstrate that the existential, possessive and locative verb is amian/mian 'exist' while the existential, possessive and locative negator is $a b o$ 'not exist'. The examples of Yami existential, possessive and locative constructions are demonstrated respectively as follows.

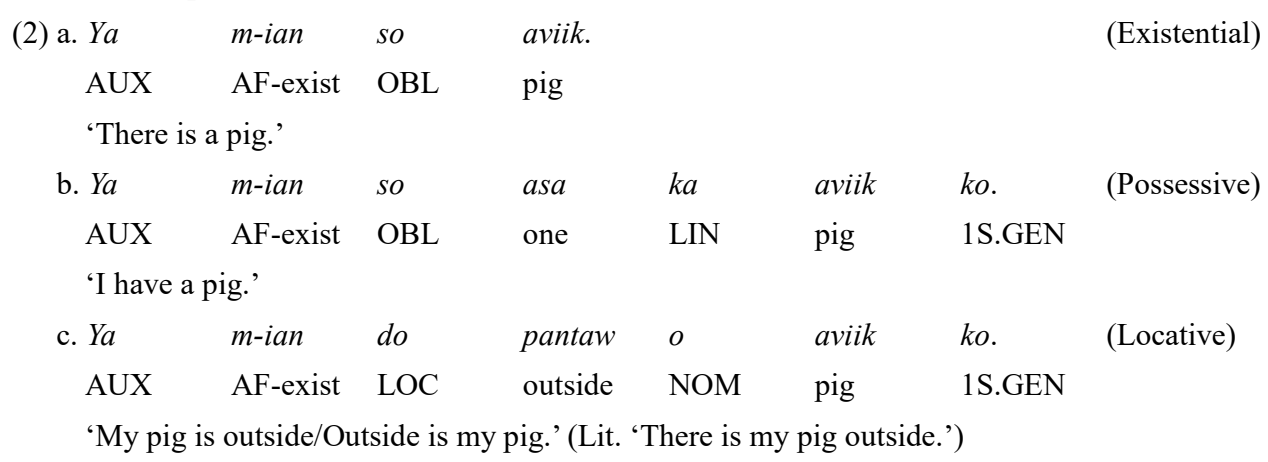

The locative construction in (2c) shows that LP/PP moves to follow the existential verb mian 'exist' at the position between the VP and the DP, which syntactically differs from the existential construction by means of the word order variation. Also, the Case marking can make the distinction between the existential and locative constructions. The DP aviik 'pig' is marked by an oblique marker in the existential construction whereas that is marked by a nominative marker in the locative construction.

The current study thus attempts to investigate existential, possessive and locative constructions of Yami language from the concepts of syntax and semantics.

\section{Two 'HAVE' structures}

Two 'HAVE' structures can be divided into (a) Y has X, (b) Y's X exists, and (c) both. Zeitoun et al (1999) mention that several Formosan languages only display the first 'HAVE' structure, such as Saisiyat and (Paran) Seediq, and the existential and possessive verb functions as a two-place predicate, with theme/possessed entity marked by an accusative marker and the locative phrase/possessor by a nominative marker. The Paran Seediq existential sentences, cited from Zeitoun et al (1999), are illustrated in (3). 
Existential, Possessive and Locative Constructions in Yami Language:

A comparative study to Formosan languages

$\begin{array}{cll}\text { (3) a. Niqan-ku } & \text { kigan } & \text { laqi. } \\ \text { exist-LF-1S.NOM } & \text { one } & \text { child } \\ \text { 'I have a child.' } & & \\ \text { b. } N i q a n-k u & \text { pila? } & \text { yaku. } \\ \text { exist-LF-1S.NOM } & \text { money } & \text { 1S.NOM } \\ \text { 'I have money.' } & & \end{array}$

On the other hand, Zeitoun et al. also contend that parts of Formosan languages manifest the second 'HAVE' structure only, such as (Truku) Seediq, Amis, Atayal, Paiwan, (Labuan) Rukai, which resembles a one-place predicate with a theme/possessed entity marked by a nominative marker and the possessor being realized by a genitive pronoun attached to the theme argument. The examples of Central Amis and Northern Paiwan, cited from Zeitoun et al. (1999), are shown respectively as follows:

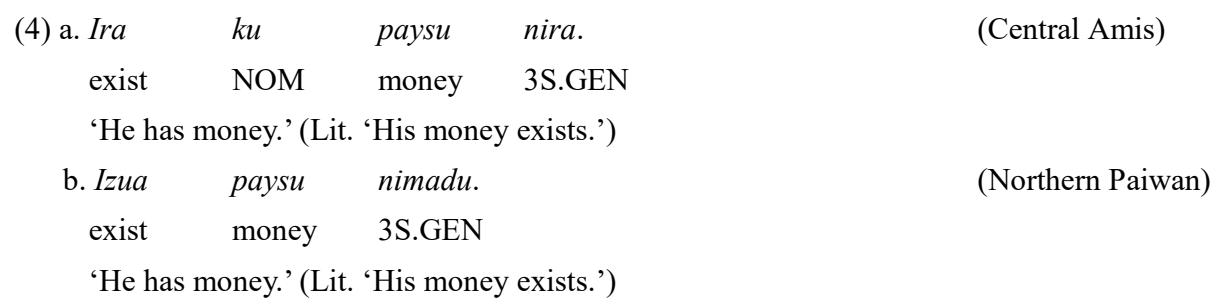

Moreover, Zeitoun et al (1999) delineate that Bunun, Kavalan, Puyuma and Mantauran Rukai show both 'HAVE' structures: (a) $Y$ has $X$ as well as (b) Y's $X$ exists. The existential sentences of Bunun and Mantauran Rukai are also illustrated in (5) and (6).

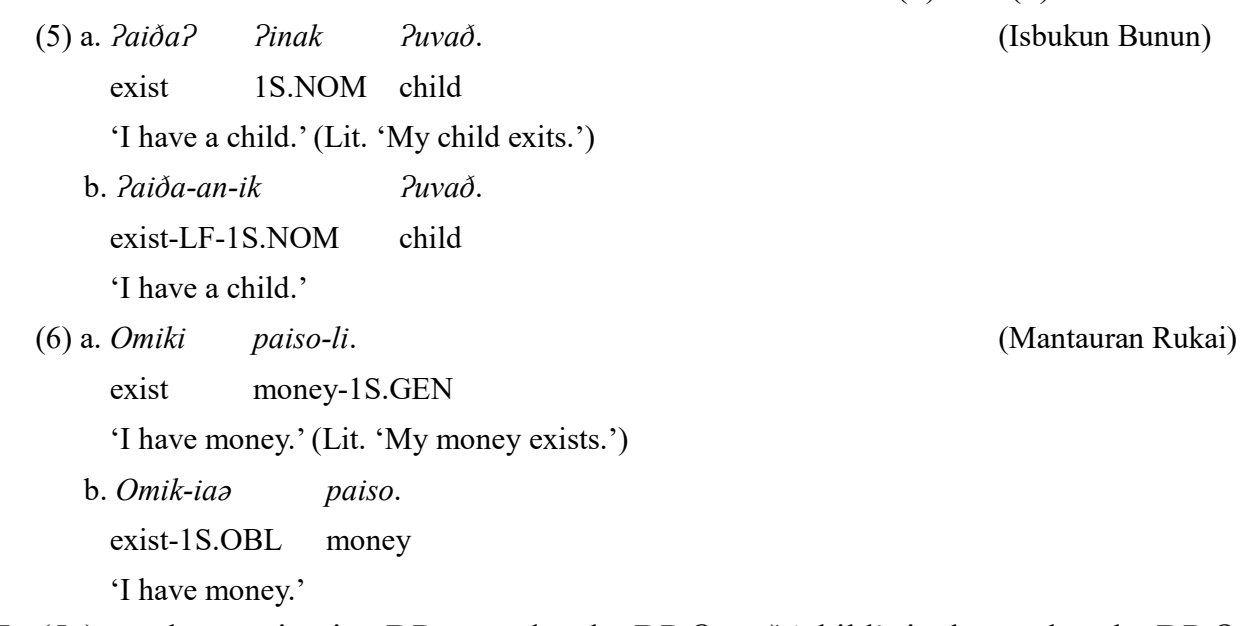

In (5a), as the nominative DP precedes the DP Puvað 'child', it shows that the DP Puvað 'child' is the possessed and the nominative DP Pinak 'I' is the possessor. (5a) indicates the second type; by contrast, in (5b), the DP $-i k$ 'I' encliticize to the existential verb with a locative focus, and it means the DP ?uvað 'child' is located at the possessor, giving an 


\section{Chihjen Cheng}

existential reading.

As a matter of fact, Yami also demonstrates both two 'HAVE' structures. Rau \& Dong $(2000,2006,2013,2018)$ claim that the possessive constructions in Yami language can show both (a) Y has $\mathrm{X}$ as well as (b) Y's X exists structures separately. Consider the following examples in Yami:

$\begin{array}{ccccl}\text { (7) a. Ya } & \text { mian } & \text { so } & \text { nizpi } & k \text { k. } \\ \text { AUX } & \text { exist } & \text { OBL } & \text { money } & \text { 1S.GEN } \\ \text { 'I have money.' } & & & \\ \text { b. } Y a & \text { mian } & o & \text { nizpi } & k o . \\ \text { AUX } & \text { exist } & \text { NOM } & \text { money } & \text { 1S.GEN } \\ \text { 'I have money,'(Lit. 'My money exists.') } & \end{array}$

Also, Chang (2000) mentions that an animate subject cannot occur in a possessive construction to be the subject ( $\mathrm{Spec}$ of $\mathrm{TP} / \mathrm{VP} / v \mathrm{P}$ ), so it syntactically differs from an existential construction. Semantically, (7b) in Yami moreover implies that the meaning is analogous to (6a) that in Mantauran Rukai, which indicates that 'I have money, and money is here (or on the speaker)', whereas (6b) and (7a) both point out that 'I have money (but it exists somewhere).' Besides, syntactically, Yami addresses $Y$ has $X$ structure by utilizing the obligatory marker, akin to what Mantauran Rukai does, while Isbukun Bunun is represented by LF. Moreover, in $Y$ 's $X$ exists structure, besides, Yami syntactically represents it by means of the nominal marker.

\section{Definiteness effects}

Definiteness effect (DE) plays a significant role in the existential constructions in a large number of languages. As a matter of fact, $\mathrm{DE}$ is universal in English and Mandarin Chinese existential constructions, and the following examples of English and Mandarin Chinese are exemplified, respectively:

(8) a. There is a/one man crying.

b. There are seven men crying.

c. ${ }^{*}$ There is the/this/that man crying.

d. There is no man crying.

e. ${ }^{*}$ There is no the/this/that man crying.

\begin{tabular}{|c|c|c|c|c|c|}
\hline (9) а. Yั̆u & $y \bar{l}$-gè & rén & $z \grave{a} i$ & $k \bar{u}$. & (Mandarin Chinese) \\
\hline HAVE & one-CL & person & PRT & cry & \\
\hline \multicolumn{6}{|c|}{ 'There is a/one man crying.' } \\
\hline b. Y̌̌u & $b \bar{a}-g \grave{~}$ & rén & $z \grave{a} i$ & $k \bar{u}$. & \\
\hline HAVE & eight-CL & person & PRT & cry & \\
\hline
\end{tabular}


Existential, Possessive and Locative Constructions in Yami Language:

A comparative study to Formosan languages

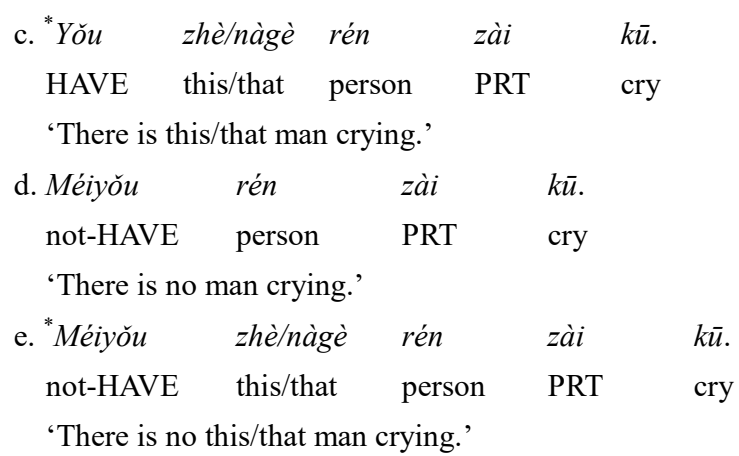

Based on (8) and (9), the sentences show that DE plays a key role in (8c), (8e), (9c) and (9d), and makes the sentences ungrammatical in existential constructions. According to a formal semantic account, these definite determiners, such as every, the, that, this and seven, are not intersectivity quantifiers, so they cannot exist in existential constructions (Keenan, 1987; Wu, 2013).

Additionally, $\mathrm{Wu}$ (2009) demonstrates in detail that DE also plays an influential role in Isbukun Bunun existential constructions, which means that non-intersectivity quantifiers are not grammatically allowed to occur in existential constructions. The examples of Isbukun Bunun existential constructions are shown below.

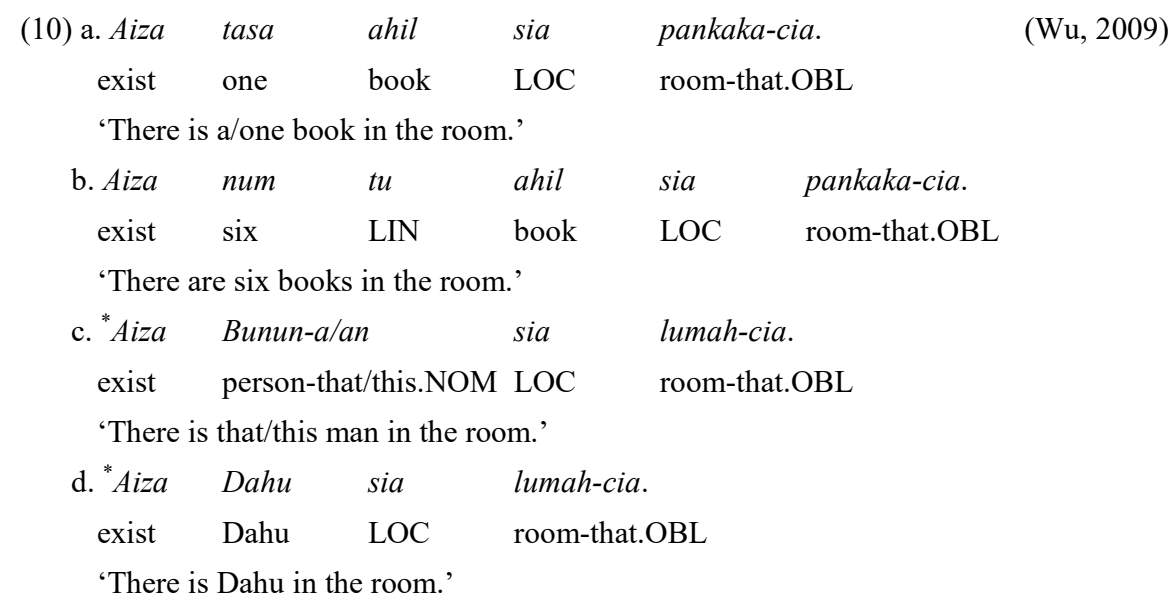

The form above demonstrates a piece of strong evidence that definite determiners are not allowed in existential constructions in support of the claim of Keenan (1987). Yami, however, shows a different way of representing generic meanings by means of the construction of amian $o$, which indicates the old information rather than new one. The 


\section{Chihjen Cheng}

examples of Yami existential sentences are shown, respectively ${ }^{\mathbb{1}}$ :

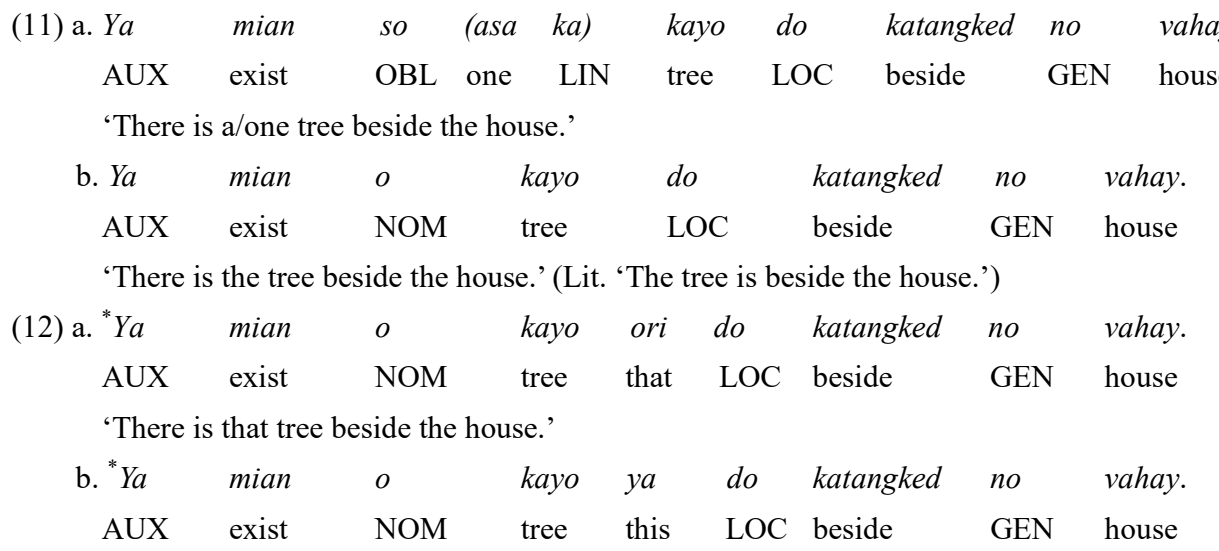

'There is this tree beside the house.'

\begin{tabular}{|c|c|c|c|c|c|c|}
\hline $\begin{array}{l}\text { (13) a. }{ }^{*} A b o \\
\text { not-exist }\end{array}$ & $\begin{array}{l}\text { so } \\
\mathrm{OBL}\end{array}$ & $\begin{array}{l}\text { kayo } \\
\text { tree }\end{array}$ & $\begin{array}{l}d o \\
\text { LOC }\end{array}$ & $\begin{array}{l}\text { katangked } \\
\text { beside }\end{array}$ & $\begin{array}{l}\text { no } \\
\text { GEN }\end{array}$ & $\begin{array}{l}\text { vahay. } \\
\text { house }\end{array}$ \\
\hline \multicolumn{7}{|c|}{ 'There is no tree beside the house.' } \\
\hline b. $A b o$ & $o$ & kayo & do & katangked & no & vahay. \\
\hline not-exist & NOM & tree & LOC & beside & GEN & house \\
\hline \multicolumn{7}{|c|}{ 'There is no such tree beside the house.' } \\
\hline 4) $Y a$ & mian & si & Salang & do & katangked & no \\
\hline AUX & exist & NOM & Salang & LOC & beside & GEN \\
\hline
\end{tabular}

'There is Salang beside the house.'

(11a) has an indefinite reading due to the oblique marker $o$ while (11b) gives a definite reading owing to the nominative marker so, that is to say, DE does not play any significant part in an existential construction. However, seeing that (12a) and (12b) are not acceptable, the free definite determiners $y a$ 'this' and ori 'that' do play fairly evident roles in the existential constructions. The findings are in support of the claim of $\mathrm{Wu}(2009)$.

Conversely, the existential negator abo 'not exist' only permits the nominative marker $o$, which indicates a definite reading, and thus (13b) is grammatical in a Yami existential construction whereas (13a), an indefinite reading, is not. Last but not least, the proper names in (14) are allowed to occur in a Yami existential construction as well, a clear-referential reading. Therefore, it appears that DE does not significantly work in the existential constructions.

To be brief, it can be rationally argued that the definite determiners, such as ori 'that' and

\footnotetext{
(1) I thank Prof. V. D-H. Rau, Ms. M-N. Dong and Ms. A. H-H. Chang for helping me judge the grammaticality of Yami existential sentences, which are illustrated in (11), (12), (13) and (14).
} 
Existential, Possessive and Locative Constructions in Yami Language:

A comparative study to Formosan languages

ya 'this', are not grammatically allowed.

\section{An analysis of small clause}

The existential, possessive and locative verb amian 'exist/have' in Yami language is semantically analogous to English existential exist/have and Chinese cúnzài 'exist' whereas it syntactically functions as English expletive there (be)/have, Chinese yǒ ' have' and Taiwan Southern Min $\bar{u}$ 'have', which can select a small clause (SC) as its secondary predicate (Stowell, 1981; Safir, 1982; Huang, 1987; Paul, 2000; Tang, 2010; and Zheng, 2013). Prior to the analysis of Yami, the examples of English, Chinese, and Taiwan Southern Min are illustrated as follows, respectively:

(15) a. There is [ $\alpha$ a man crying in the room].

$$
\begin{aligned}
& \text { b. Tā yǒu [ayī-běn shū hěn yǒuqù }] \text {. } \\
& \text { he HAVE one-CL book very interesting } \\
& \text { 'He has a book (which is) very interesting.' }
\end{aligned}
$$

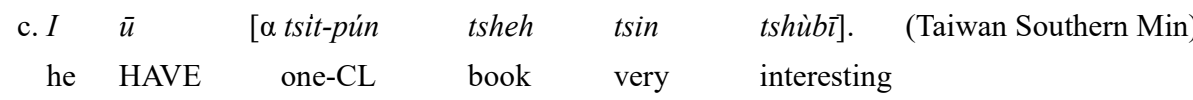

'He has a book (which is) very interesting.'

Based on (15), the sentences manifest that these three existential verbs can select a secondary predicate as their complements; in other words, what secondary-predicate phrases that the existential verbs select can be syntactically diagnosed as small clauses, that is to say, analyzed as a [ $\alpha$ DP XP] construction in support of the claim of Stowell, 1981; Safir, 1982; Huang, 1987 and Paul, 2000.

A small clause has a subject-predicate of a clause, but that lacks tense, neither finitive nor infinitive. The small clause is closely related to the phenomena of raising-to-object, exceptional case-marking (ECM), accusativus cum infinitivo, and object control, which all indicate the analysis of a mono-clause (Haegeman, 1991; Grano, 2012). According to ECM, the small clause actually denotes an interpretation where the subject of an embedded infinitival verb seems to show in the superordinate clause. Additionally, it is unexpectedly marked with an object case morphologically if it is a pronoun in English.

All in all, an SC involves an embedded clause (or bi-clause), relative clauses and mono-clauses. Yami DP/NP will be thus marked by an oblique marker, which supports the above claim from the examples in this study.

Furthermore, in Austronesian languages, Keenan (1976) claims that the postverbal material is structurally similar to a complex NP, and it thus can be treated on a par with a relative clause with the relative pronoun and/or complementizer omitted, as shown in (16).

$$
\begin{array}{rlll}
\text { (16) a. Misy } & {[\text { zaza }} & \text { izay } & \text { mihara }] \\
\text { exist } & \text { child } & \text { that } & \text { sing }
\end{array}
$$




\section{Chihjen Cheng}

'There is a child crying.'

b. ${ }^{1}$.

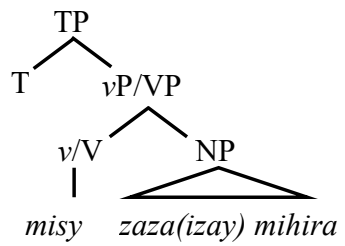

Notice that in Malagaw, an NP precedes the modifying clause (Paul, 2000). Besides, Wu (2009) states that the existential verb aiza 'exist' in Isbukun Bunun takes a small clause as its complement, and the simple/complex sentences are illustrated below:

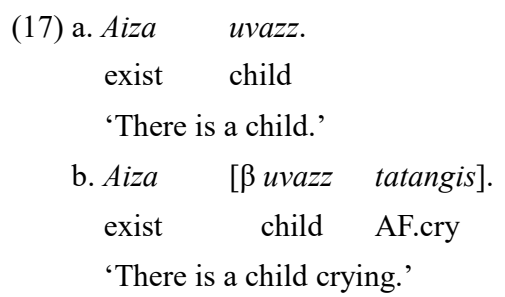

The phrase $\beta$ in (17b) is syntactically analyzed as a small clause, and the syntactic tree is given in (18a), in contrast with (17a), as given in (18b):

(18) a.

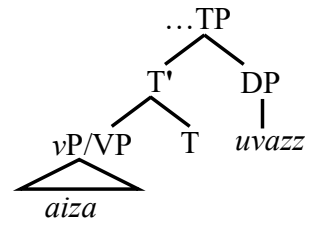

b.

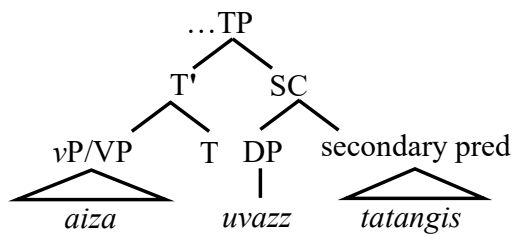

What phrases the linker $a$ chooses in a Yami existential construction can be diagnosed as a relative clause. Chang \& Rau (2017) claim that Yami relative clauses are connected to the head nouns by the linker $a$. The head noun hence can either follow the relative clause or precede it. In addition, Rau \& Dong (2006) claim that if a relative clause precedes the head noun, it restricts the head noun. However, when it follows a noun, it describes the characteristics of the head noun, as shown in (19), respectively.

\footnotetext{
(1) This syntactic tree is redrawn by this study in terms of a current analysis of Minimalist Program, and thus it is a bit different from that in Wu's work.
} 
Existential, Possessive and Locative Constructions in Yami Language: A comparative study to Formosan languages

$\begin{array}{llllllll}\text { (19) a. } k \text { o } & \text { ni-ma-cita } & o & {[j i} & \text { yakneng] } & a & \text { kanakan. } \\ \text { 1S.GEN } & \text { PA-PF-see } & \text { NOM } & \text { Neg } & \text { SUB.claim } & \text { LIN } & \text { child } \\ \text { 'I saw that hyperactive child.' } & & & & \\ \text { b. } k \text { r } & \text { ni-ma-cita } & o & \text { kanakan } & a & {[j i} & \text { yakneng]. } \\ \text { 1S.GEN } & \text { PA-PF-see } & \text { NOM } & \text { child } & \text { LIN } & \text { NEG } & \text { SUB.claim }\end{array}$

'I saw that child who was very hyperactive.'

As a relative clause follows the head noun, it will result in a relative-clause reading. The current study hence claims that the existential verb amian/abo 'exist/not exist' selects a small clause, as illustrated in (20).

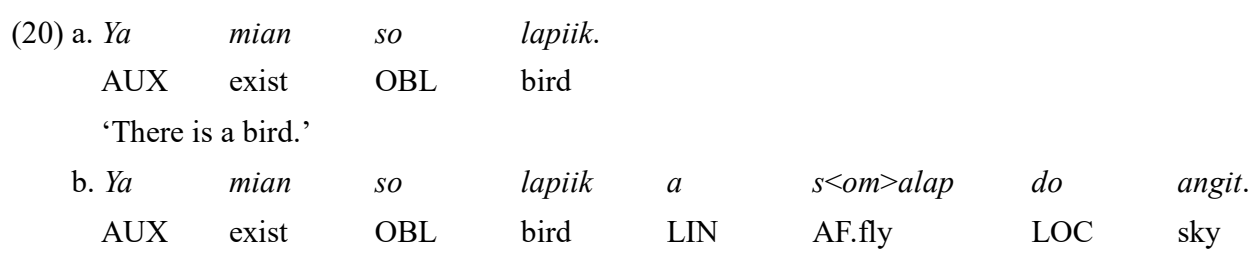

'There is a bird (which is) flying in the sky.'

(21) a.

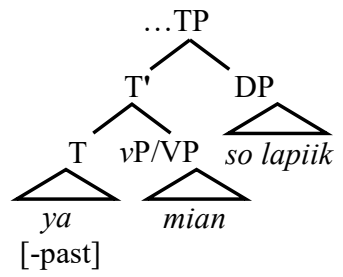

b.

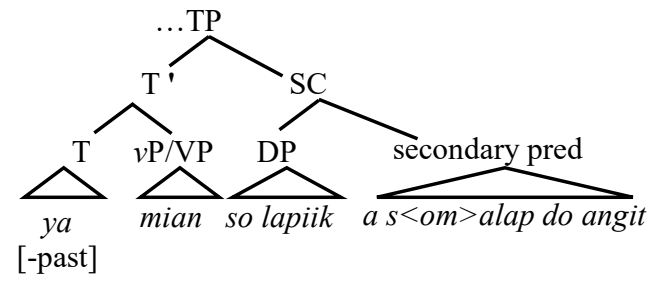

Based on the syntactic analysis of Bunun existential sentences, this study also motivates the structure for Yami existential constructions as presented in (22b).
(22) a. Aiza proEXPL [SC DP theme XP predicate]
(Bunun) (Wu, 2009)
b. Amian/Abo proEXPL [SC DP theme XP predicate]
(Yami)

Compared with the underlying form of English constructions, it is regarded as [S exist there [SC DP theme XP predicate]], and English language is a non null-subject language whose grammar forbids an independent clause to lack an explicit subject. On the contrary, Mandarin Chinese is a null-subject language that permits an explicit subject and therefore the expletive subject in Yami is not obligatory to occur in the Specifier of TP in a syntactic structure. Besides, Extended Project Principle (EPP) is another factor to manifest that Yami 


\section{Chihjen Cheng}

language is a null subject language, and there is an expletive pro in a Yami existential construction. EEP points out the obligatoriness of subjects, proposed by Chomsky (1995). Since Yami does not bear any EPP feature, it further indicates that it does not obligatorily require the Spec of $v \mathrm{P}$ to move to the Spec of TP to be the subject. It points out that there exists a pro expletive in Yami existential, possessive and locative constructions. Besides, another major motivation for claiming that the existential verb amian 'exist' selects a small clause is Huang's (1987) mentions of the existential verb taking an embedded clause, like Mandarin Chinese yǒ ' 'have/exist', which belongs to an SC as well. Therefore, it is argued that the existential verb amian 'exist' in Yami existential, possessive and locative constructions does choose a small clause.

\section{Conclusion}

I have delineated a picture of existential, possessive and locative constructions on three issues: (i) two 'HAVE' structures, (ii) Definiteness Effect (DE), as well as (iii) an analysis of small clause. Therefore, the contribution of this research is the argument that Yami language has two 'HAVE' structures and DE only plays a key role with respect to the free definiteness determiners, such as ori 'that' and $y i$ 'this'. Additionally, the study has argued that $\mathrm{E}, \mathrm{P}$ and $\mathrm{L}$ sentences in Yami language cannot be properly analyzed in the line with the complex NP/DP account nor the NP/DP-XP analysis. Rather, a clausal treatment is more effective. Hence, what syntactic constituent the existential verb/negator amian/abo 'exist/not exist' selects is diagnosed as a small clause, and the small clause the existential verb/negator amian/abo 'exist/not exist' selects is the relative clause.

$\begin{array}{ll}\text { Abbreviations } \\ 1 & \text { first person } \\ 3 & \text { third person } \\ \text { AF } & \text { active force } \\ \text { AUX } & \text { auxiliary } \\ \text { CL } & \text { classifier } \\ \text { DE } & \text { definiteness effect } \\ \text { DP } & \text { determiner phrase } \\ \text { EEP } & \text { extended project principle } \\ \text { EXPL } & \text { expletive } \\ \text { GEN } & \text { genitive case } \\ \text { LF } & \text { location force } \\ \text { LIN } & \text { linker } \\ \text { LOC } & \text { locative } \\ \text { LP } & \text { locative phrases } \\ \text { Neg } & \text { negation } \\ \text { NOM } & \text { nominative case } \\ \text { NP } & \text { noun phrase } \\ \text { OBL } & \text { oblique case }\end{array}$

66

$\begin{array}{ll}\text { P } & \text { plural } \\ \text { PA } & \text { pre-affix } \\ \text { PF } & \text { passive force } \\ \text { PP } & \text { prepositional phrases } \\ \text { Pred } & \text { predicate/predication } \\ \text { Pro } & \text { pronominal anaphor } \\ \text { proEXPL } & \text { pro expletive } \\ \text { PRT } & \text { particle } \\ \text { S } & \text { singular } \\ \text { SC } & \text { small clause } \\ \text { Spec } & \text { specifier } \\ \text { SUB } & \text { subject } \\ \text { T } & \text { tense } \\ \text { T' } & \text { tense bar } \\ \text { TP } & \text { tense phrase } \\ \text { VP } & \text { verb phrase } \\ \text { vP } & \text { light verb phrase } \\ \text { XP } & \text { X phrase }\end{array}$

Macrolinguistics (2020) 


\section{Existential, Possessive and Locative Constructions in Yami Language: A comparative study to Formosan languages}

\section{References}

Blust, R. 2009. The Austronesian Languages [M]. Canberra: Pacific Linguistics.

Chang, A. H-H. \& V. D. Rau. 2017. A Corpus-based Analysis of Word Order Variation in Yami Relative Clause Construction [J]. Asia-Pacific Language Variation, 3(1):95-122.

Chang, C. H. 2000. Reference Grammar to Yami Language [M]. Taipei: Yuan Liou Publishing.

Chomsky, N. 1995. The Minimalist Program [M]. Cambridge, MA: MIT Press.

Freeze, R. 1992. Existentials and Other Locatives [J]. Linguistics, 68(3):553-595.

Grano, T. 2012. Control and Restructuring at the Syntax-semantics Interface [D]. Ph.D. Dissertation, Chicago: University of Chicago.

Keenan, E. 1976. Remarkable Subjects in Malagasy [A]. In C. Li (ed.). Subject and Topic [C]. New York: Academic Press, 247-301.

Keenan, E. 1987. A Semantic Definition of 'Indefinite NP' [A]. In E. Reuland \& A. ter Meulen (eds.). The Representation of (In)Definiteness [C]. Cambridge, MA: MIT Press, 286-317.

Kuno, S. 1971. The Position of Locatives in Existential Sentences [J]. Linguistic Inquiry, 2:233-278.

Haegeman, L. M. V. 1991. Introduction to Government and Binding Theory [M]. Oxford: Blackwell Publishers.

Huang, J. C-T. 1987. Existential Sentences in Chinese and (In)Definiteness [A]. In E. J. Reuland \& A. G. B. ter Meulen (eds.). The Representation of (In)Definiteness [C]. Cambridge, MA: MIT Press, 226-253.

Lapolla, R. \& D. Poa. 2006. On Describing Word Orders [A]. In F. Ameka, A. Dench \& N. Evans (eds.). Catching Language: The standing challenge of grammar writing $[\mathrm{C}]$. Berlin: Mouton de Gruyter, 269-295.

Lyons, J. 1967. A Note on Possessive, Existential and Locative Sentences [J]. Foundations of Language, 3(4):390-396.

Paul, I. 2000. Malagasy Existentials: A Syntactic Account of Specificity [A]. In I. Paul, V. Phillips, L. Travis (eds.). Formal Issues in Austronesian Linguistics. Studies in Natural Language and Linguistic Theory, $49[\mathrm{C}]$. Dordrecht: Springer.

Rau, V. D-H. \& M-N. Dong. 2000. Yami Language Textbook [M]. Taipei: Crane Publishing.

Rau, V. D-H. 2005. Iconicity and Tense, Aspect and Mood in Yami [J]. Concentric, 31(1):2-21.

Rau, V. D-H. \& M-N. Dong. 2006. Yami Texts with Reference Grammar and Dictionary [M]. Taipei: Academia Sinica.

Rau, D-H. V., M-N. Dong \& M-C. Yang. 2007a. Digital Archiving Yami Language Documentation [OL] Providence University. (http://yamiproject.cs.pu.edu.tw/yami)

Rau, V. D-H., M-N. Dong \& M-C. Yang. 2007b. Yami E-learning [OL]. Providence University. (http:// yamiproject.cs.pu.edu.tw/elearn)

Rau, V. D-H., M-N. Dong \& M-C. Yang. 2007c. Yami Online Dictionary [OL]. Providence University. (http://yamibow.cs.pu.edu.tw)

Rau, V. D-H. \& M-N. Dong. 2013. Existential, Possessive \& Locative Constructions [Z]. Manuscript.

Rau, V. D-H. \& M-N. Dong. 2018. An Introduction to Yami Grammar [M]. Taipei: Council of Indigenous Peoples.

Safir, K. 1982. Syntactic Chains and the Definiteness Effect [D]. Ph.D. Dissertation, Cambridge, MA: MIT.

Stowell, T. 1981. Origins of Phrase Structure [D]. Ph.D. Dissertation, Cambridge, MA: MIT.

Tang, T-C. 2010. Paper Collections of Chinese Grammar [M]. Taipei: Pyramid Publishing.

Wu, I. H-H. 2009. Existential Constructions in Isbukun Bunun [J]. Oceanic Linguistics, 48(2):364-378.

Wu, H. J-S. 2013. Chapter Six: Quantifiers [Z]. Ms, Chiayi: National Chung Cheng University.

Zeitoun, E., L. M. Huang, M. M. Yeh \& A. H. Chang. 1999. Existential, Possessive, and Locative Constructions in Formosan Languages [J]. Oceanic Linguistics, 38(1):1-42.

Zheng, A. 2013. The Word $\bar{U}$ 'HAVE' In Taiwan Southern Min [Z]. Ms, Chiayi: National Chung Cheng University. 